\title{
Deinobacterium chartae gen. nov., sp. nov., an extremely radiation-resistant, biofilm-forming bacterium isolated from a Finnish paper mill
}

\author{
Correspondence \\ Jaakko V. Ekman \\ jaakko.ekman@helsinki.fi
}

\author{
Jaakko V. Ekman, ${ }^{1}$ Mari Raulio, ${ }^{1}$ Hans-Jürgen Busse, ${ }^{2}$ David P. Fewer ${ }^{1}$ \\ and Mirja Salkinoja-Salonen ${ }^{1}$
${ }^{1}$ Department of Food and Environmental Sciences, P.O. Box 56, FIN 00014 University of Helsinki, Finland
${ }^{2}$ Institut für Bakteriologie, Mykologie und Hygiene, Veterinärmedizinische Universität, A-1210 Wien, Austria

\begin{abstract}
A rod-shaped, non-spore-forming, non-motile, aerobic, oxidase and catalase-positive and radiation-resistant bacterium (designated strain $\mathrm{K} 4.1^{\top}$ ) was isolated from biofilm collected from a Finnish paper mill. The bacterium grew as pale pink colonies on oligotrophic medium at 12 to $50{ }^{\circ} \mathrm{C}$ (optimum 37 to $45^{\circ} \mathrm{C}$ ) and at $\mathrm{pH} 6$ to 10.3. The DNA G+C content of the strain was $66.8 \mathrm{~mol} \%$. According to $16 \mathrm{~S}$ rRNA gene sequence analysis, strain $\mathrm{K} 4.1^{\top}$ was distantly related to the genus Deinococcus, sharing highest similarity with Deinococcus pimensis (90.0\%). In the phylogenetic tree, strain $\mathrm{K} 4.1^{\top}$ formed a separate branch in the vicinity of the genus Deinococcus. The peptidoglycan type was $A 3 \beta$ with L-Orn-Gly-Gly and the quinone system was determined to be MK-8. The polar lipid profile of strain $\mathrm{K} 4.1^{\top}$ differed markedly from that of the genus Deinococcus. The predominant lipid of strain $\mathrm{K} 4.1^{\top}$ was an unknown aminophospholipid and it did not contain the unknown phosphoglycolipid predominant in the polar lipid profiles of deinococci analysed to date. Two of the predominant fatty acids of the strain, 15:0 anteiso and 17:0 anteiso, were lacking or present in small amounts in species of the genus Deinococcus. Phylogenetic distinctness and significant differences in the polar lipid and fatty acid profiles suggest classification of strain $\mathrm{K} 4.1^{\top}$ as a novel genus and species in the family Deinococcaceae, for which we propose the name Deinobacterium chartae gen. nov., sp. nov. The type strain is $\mathrm{K} 4.1^{\top}$ $\left(=\right.$ DSM $21458^{\top}=$ HAMBI $\left.2721^{\top}\right)$.
\end{abstract}

The order Deinococcales currently consists of two families, Deinococcaceae (Battista \& Rainey, 2001) and Trueperaceae (Albuquerque et al., 2005). Both families contain only one genus, Deinococcus and Truepera, respectively. The genus Truepera holds only one species, Truepera radiovictrix (Albuquerque et al., 2005). The genus Deinococcus is comprised of 39 species at the time of writing and new species are frequently described (ten in 2009). Members of the genus Deinococcus were isolated from environments ranging from arid soils (Hirsch et al., 2004; Rainey et al., 2005, 2007; de Groot et al., 2005; Callegan et al., 2008; Yuan et al., 2009) to water (Kämpfer et al., 2008; Im et al., 2008) and geothermal springs (Asker et al., 2008, 2009; Ferreira et al., 1997). Truepera radiovictrix was also isolated

Abbreviations: PMW, paper machine water; SEM, scanning electron microscopy; TEM, transmission electron microscopy.

The GenBank/EMBL/DDBJ accession number for the 16S rRNA gene sequence of strain $\mathrm{K} 4.1^{\top}$ is $\mathrm{AM} 988777$.

Four supplementary figures and a supplementary table are available with the online version of this paper. from a geothermal spring (Albuquerque et al., 2005). Deinococcus geothermalis is known as a common colonizer in paper machines (Kolari et al., 2003; Peltola et al., 2008).

Strain $\mathrm{K} 4.1^{\mathrm{T}}$ was isolated from a biofilm growing in the wire section of a Finnish paper mill (wire water temperature $45-50{ }^{\circ} \mathrm{C}$ ) producing folding boxboard. Biofilm was collected with a sterile plastic tube and transported to the laboratory on the same day. The biofilm was washed with sterile tap water to remove loosely attached bacteria. Washed pieces of the biofilm were incubated on a polystyrene 12-well plate in sterilized board mill wire water amended with $1.0 \mathrm{~g}$ soluble starch and $0.1 \mathrm{~g}$ yeast extract per litre. After 2 days of shaking at 160 r.p.m., $48{ }^{\circ} \mathrm{C}$, freshly grown biofilm from the edges of the well was streaked on a plate of paper machine water (PMW) agar (wire water from the machine in question supplemented with $1.0 \mathrm{~g}$ soluble starch, $0.1 \mathrm{~g}$ yeast extract and $15 \mathrm{~g}$ agar per litre) and grown for 4 days at $48{ }^{\circ} \mathrm{C}$. A pale pink colony ( strain $\mathrm{K} 4.1^{\mathrm{T}}$ ) was isolated from this plate and subcultured until pure on PMW agar plates. 
On R2A agar $\left(\mathrm{g} \mathrm{l}^{-1}\right.$ : yeast extract 0.5 , meat peptone 0.5 , Casamino acids 0.5, glucose 0.5, starch 0.5, $\mathrm{K}_{2} \mathrm{HPO}_{4} 0.3$, $\mathrm{MgSO}_{4} 0.05$, sodium pyruvate 0.3 , agar 15 ), strain $\mathrm{K} 4.1^{\mathrm{T}}$ grew as pale pink colonies of approximately $2 \mathrm{~mm}$ diameter after 2 days at $45^{\circ} \mathrm{C}$. Strain K4.1 $1^{\mathrm{T}}$ grew on R2A plates at 12 to $50{ }^{\circ} \mathrm{C}$, but not at $55{ }^{\circ} \mathrm{C}$, with an optimum between 37 and $45^{\circ} \mathrm{C}$. Growth was observed after 4 days of incubation (160 r.p.m.) at $45{ }^{\circ} \mathrm{C}$ at $\mathrm{pH}$ from 6.0 to 10.3 , tested in increments of $0.3-0.5 \mathrm{pH}$ units in $\mathrm{R} 2$ broth $\left(\mathrm{g} \mathrm{l}^{-1}\right.$ : yeast extract 0.5 , meat peptone 0.5 , Casamino acids 0.5 , glucose 0.5 , starch $0.5, \mathrm{~K}_{2} \mathrm{HPO}_{4} 0.3, \mathrm{MgSO}_{4} 0.05$, sodium pyruvate 0.3 ) buffered with $12 \mathrm{mM}$ MES, for $\mathrm{pH}$ range 5.9-6.9, CHES, for $\mathrm{pH}$ range 8.2-9.9, or CAPS, for $\mathrm{pH}$ range 9.7-11.0. Growth occurred on R2A plates with $3 \%$ $(\mathrm{w} / \mathrm{v})$ but not with $5 \% \mathrm{NaCl}\left(5\right.$ days at $\left.45{ }^{\circ} \mathrm{C}\right)$. No motility of the cells of strain K4.1 ${ }^{\mathrm{T}}$ was observed with a microscope and no spores were observed in 5-day-old cultures stained with malachite green. No anaerobic (Anaero Gen atmosphere generation system; Oxoid) growth was observed on medium in the absence of added carbohydrate [tryptic soy agar (TSA), $\mathrm{g} \mathrm{l}^{-1}$ : casein peptone 15 , soy peptone $5, \mathrm{NaCl}$ 5, agar 15] for 3 days at $45^{\circ} \mathrm{C}$.

Oxidation of carbon sources by strain $\mathrm{K} 4.1^{\mathrm{T}}$ was analysed by using Phenotypic MicroArray plates PM1 and PM2A (Biolog) according to the manufacturer's instructions. Results were measured with a plate reader $\left(\mathrm{OD}_{600 \mathrm{~nm}}\right.$; Victor $^{3}$, Perkin-Elmer) after $48 \mathrm{~h}$ of incubation from duplicate plates. A reaction was considered positive when the $\mathrm{OD}_{600}$ was $>0.08$ units higher than that of the negative control without carbon source in both duplicate plates. Strain K4.1 ${ }^{\mathrm{T}}$ oxidized polymers of $\alpha$-1,4-linked glucoses (dextrin, $\gamma$-cyclodextrin and starch) as well as $\alpha-1,3-$ and $\alpha$ 1,6-linked di- and trisaccharides (raffinose, turanose, palatinose and gentiobiose) but not 1,4-linked glucosides, sucrose, maltose or cellobiose. Strain $\mathrm{K} 4.1^{\mathrm{T}}$ oxidized pentose (D-xylose) and deoxyhexose (L-fucose) but not the monomeric hexoses fructose, mannose or glucose. These findings indicate that the pentose phosphate cycle may represent the preferred pathway for glucose utilization rather than glycolysis or that strain $\mathrm{K} 4.1^{\mathrm{T}}$ is defective in the uptake of hexoses. Starch degradation was tested on R2A agar supplemented with $10 \mathrm{~g}$ starch $\mathrm{l}^{-1}$. Formation of a clearing zone around bacterial growth proved that strain $\mathrm{K} 4.1^{\mathrm{T}}$ is able to utilize starch. It appears that glucosecontaining polymers are metabolized via cyclodextrins rather than exocellularly hydrolysed to glucose. The strain oxidized gelatin and several L-amino acids (alanine, aspartic acid, asparagine, glutamine, histidine and lysine) but not L-valine, L-glycine, L-hydroxyproline or L-phenylalanine. Of the monocarboxylic acids, the strain oxidized glycolic, propionic, butyric, caproic and $p$ - and $m$ hydroxyphenylacetic acids but not benzoic or 2-hydroxybenzoic acid, or lactic or capric acid. Of the dicarboxylic acids, it oxidized succinic, fumaric, $m$-tartaric and malonic acids but not D- and L-tartaric acids. Several intermediates of the TCA cycle (acetic, pyruvic, L-malic or $\alpha$-ketoglutaric acid) did not support the growth of strain $\mathrm{K} 4.1^{\mathrm{T}}$.
Utilization of nitrogen, phosphorus and sulphur sources by strain K4.1 ${ }^{\mathrm{T}}$ were tested on Phenotypic MicroArray plates PM3B and PM4A (Biolog) using succinate as the carbon source. Inorganic nitrogen and phosphorus sources were not utilized when succinate was the carbon source. Four amino acids, three hexosamines, seven dipeptides, uric acid and alloxan were used as sole sources of nitrogen. Also, six nucleosides but not the corresponding purine (excepting guanine) or pyrimidine bases were used as sole sources of nitrogen. Nucleotide 5' monophosphates were the only compounds used as the sole sources of phosphorus when succinate was the carbon source. Strain $\mathrm{K} 4.1^{\mathrm{T}}$ did not grow on any of the tested sulphur sources when succinate was supplied as the carbon source. A list of the oxidized or utilized sources of carbon, nitrogen and phosphorus is provided in the species description.

Production of acid and gas from carbohydrates, reduction of nitrate and nitrite, and oxidase activity were tested at $45{ }^{\circ} \mathrm{C}$ as described by MacFaddin (2000). Strain K4.1 ${ }^{\mathrm{T}}$ produced acid from glucose, fructose and maltose but not from sucrose, mannitol, ribose, lactose, xylose, myo-inositol, sorbose or arabinose. Strain K4. $1^{\mathrm{T}}$ did not produce gas from any of the tested carbohydrates. Reference strains Deinococcus radiodurans DSM 20539 $9^{\mathrm{T}}$ and Deinococcus geothermalis $11300^{\mathrm{T}}$ produced no acid or gas from any of the tested carbohydrates, which is in line with the genus description (Battista \& Rainey, 2001). Truepera radiovictrix DSM $17093^{\mathrm{T}}$ did not grow on this medium [standard broth base media: $1 \%(\mathrm{w} / \mathrm{v})$ peptone, $0.1 \%$ meat extract, $0.5 \% \mathrm{NaCl}, 0.5 \%$ agar, $0.002 \%$ phenol red] or on other media composed of peptones without carbohydrate $[3.3 \times$ peptone yeast extract (PYE): $1 \%(\mathrm{w} / \mathrm{v})$ peptic digest of casein, $1 \%$ yeast extract, $1.5 \%$ agar; and TSA]. Strain K4.1 ${ }^{\mathrm{T}}$, similarly to Deinococcus radiodurans DSM $20539^{\mathrm{T}}$ and Deinococcus geothermalis $11300^{\mathrm{T}}$, was oxidase-positive (indicator $N^{\prime}, N^{\prime}, N^{\prime}, N^{\prime}$-tetramethyl-p-phenylenediamine dihydrochloride) but did not reduce nitrate.

For ultrathin sections, strain $\mathrm{K} 4.1^{\mathrm{T}}$ was grown on TSA for 3 days at 37 or $45^{\circ} \mathrm{C}$, fixed in phosphate $(0.1 \mathrm{M}, \mathrm{pH} 7.2)$ buffered $2.5 \%$ glutaraldehyde for $2 \mathrm{~h}$, and rinsed with phosphate buffer three times. Cells were secondary fixed in $1 \%$ osmiumtetroxide at $4{ }^{\circ} \mathrm{C}$ for $1 \mathrm{~h}$. After dehydration in a series of ethanol concentrations (50 to 70 to 96 to $100 \%$ ) and $100 \%$ acetone, the cells were embedded in epon (Epon 812, Electron Microscopy Sciences). Ultrathin sections were cut, stained with uranium acetate and lead citrate and examined by transmission electron microscopy (TEM; JEOL 1200EX II). For field emission scanning electron microscopy (SEM), strain $\mathrm{K} 4.1^{\mathrm{T}}$ was grown in R2-broth for 3 days at $37{ }^{\circ} \mathrm{C}$ and fixed, dehydrated and examined as described previously (Raulio et al., 2008).

Strain $\mathrm{K} 4.1^{\mathrm{T}}$ is a rod-shaped bacterium (Fig. 1) and cells measured from TEM images (not shown) of negatively stained cells grown on TSA for 3 days at $45{ }^{\circ} \mathrm{C}$ were $0.8-$ $1.3 \mu \mathrm{m}$ wide and $1.4-2.5 \mu \mathrm{m}$ long. Cells were longer when grown in rich liquid medium [tryptic soy broth (TSB), 

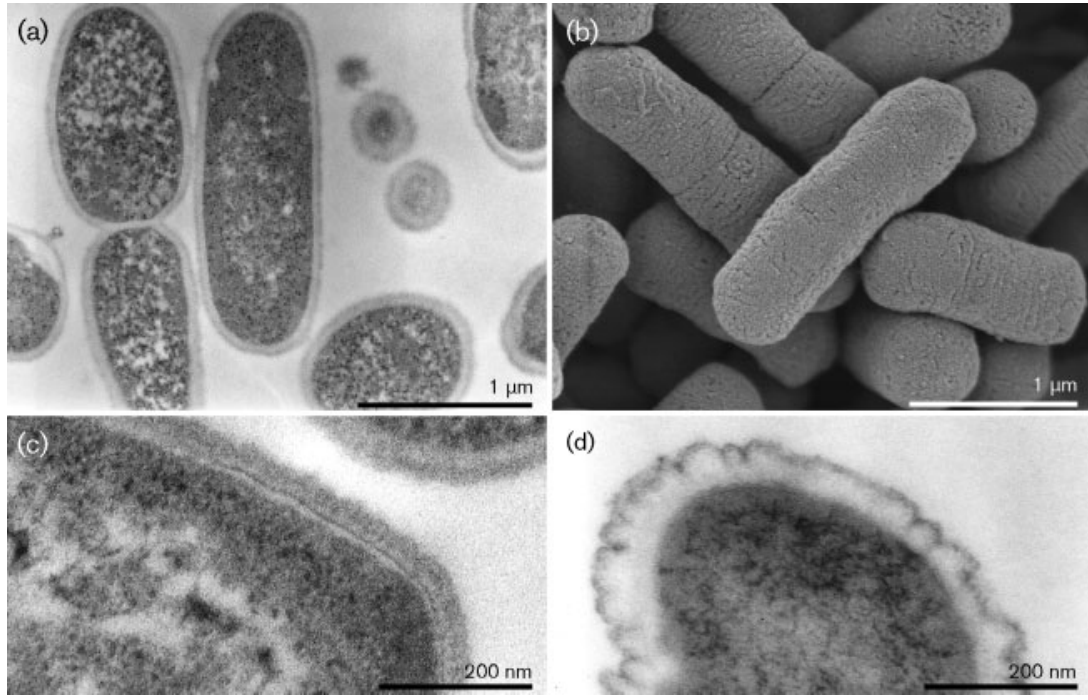

Fig. 1. Electron micrographs of strain $\mathrm{K} 4 \cdot 1^{\top}$. (a) Ultrathin section examined by TEM showing cell size and morphology. (b) Ultrastructure of cell surfaces examined by SEM. (c, d) Cell wall structure of strains $\mathrm{K} 4.1^{\top}$ and $D$. geothermalis E50051, respectively. $\mathrm{g}^{-1}$ : casein peptone 17 , soy peptone $3, \mathrm{NaCl} 5, \mathrm{~K}_{2} \mathrm{HPO}_{4}$ 2.5, glucose 2.5] at $45^{\circ} \mathrm{C}$ for 1 day $(3-8 \mu \mathrm{m})$ and filamentous (up to $40 \mu \mathrm{m}$ long) after 2 days (Supplementary Fig. S1a and b, available in IJSEM Online).

In transmission electron micrographs the cell wall of strain K4.1 ${ }^{\mathrm{T}}$ lacked an outer membrane (Fig. 1c) and in the scanning electron micrographs the cell surface resembled that of Gram-positive bacteria; no shrinkage of any outer membrane was visible (Fig. 1b). Strain K4.1 ${ }^{\mathrm{T}}$ did not lyse in $3 \% \mathrm{KOH}$ and possessed no aminopeptidase. However, the cells stained Gram-negatively, even very young cultures stained after $11 \mathrm{~h}$ of incubation on $\mathrm{R} 2 \mathrm{~A}$ at $45^{\circ} \mathrm{C}$ (data not shown).

The cell envelope of strain $\mathrm{K} 4.1^{\mathrm{T}}$ had a multilayered appearance (Fig. 1c), but was less complex than that of many species of the genus Deinococcus (Battista \& Rainey, 2001; Ferreira et al., 1997). It was very different from the cell envelope of the paper machine isolate Deinococcus geothermalis E50051 (Fig. 1d), which, like the type strain of Deinococcus geothermalis (Ferreira et al., 1997), was enclosed in a capsule-like structure. Cross-sections of cells of strain $\mathrm{K}_{4} 1^{\mathrm{T}}$ resembled more those of Deinococcus radiopugnans (Battista \& Rainey, 2001).

Inclusion bodies (Supplementary Fig. S2) had a yellow fluorescence when stained with DAPI (4'-6-diamidino-2phenylindole), possibly representing polyphosphate (Tijssen et al., 1982).

Resistance of strain $\mathrm{K} 4.1^{\mathrm{T}}$ to ionizing radiation was tested as described by Zimmerman \& Battista (2006). One millilitre aliquots of an overnight culture grown in TSB were irradiated with doses of $0,2,4,7$ and $10 \mathrm{kGy}$ $( \pm 10 \%)$ at a rate of $0.17-0.29 \mathrm{kGy} \mathrm{h}^{-1}$. After irradiation, tenfold dilution series were prepared, appropriate dilutions plated in triplicate on R2A (strain $\mathrm{K} 4.1^{\mathrm{T}}, 45^{\circ} \mathrm{C}$ ), on DSMZ medium 53: corynebacterium agar (Deinococcus radiodurans, $28{ }^{\circ} \mathrm{C}$ ) or on plate count agar (Escherichia coli, $37^{\circ} \mathrm{C}$ ) and the colonies counted after growth for 1-2 days. Non-radiated controls were maintained at room temperature and plated simultaneously with the irradiated bacteria. Deinococcus radiodurans DSM $20539^{\mathrm{T}}$ was used as a radiation-resistant reference and E. coli ATCC 51739 as a sensitive reference. Strain $\mathrm{K} 4.1^{\mathrm{T}}$ resisted radiation similarly to the type strain of Deinococcus radiodurans, i.e. lost less than one log of viability upon exposure to $10 \mathrm{kGy}$ (Supplementary Fig. S3). This characteristic confirms relatedness of strain K4. $1^{\mathrm{T}}$ to Truepera radiovictrix (Albuquerque et al., 2005) and Deinococcus radiodurans and distinguishes it from the more distantly related taxa of the genus Thermus, such as Thermus aquaticus and Thermus thermophilus (Albuquerque et al., 2005; Omelchenko et al., 2005).

The $16 \mathrm{~S}$ rRNA gene sequence of strain $\mathrm{K} 4.1^{\mathrm{T}}$ shared highest similarities with the type strains of Deinococcus pimensis $(90.0 \%)$ and Deinococcus peraridilitoris (89.6\%) (according to similarity table analysis, www.eztaxon.org; Chun et al., 2007). Levels of sequence similarity to all of the other type strains of the recognized species of the genus Deinococcus ranged from $89.4 \%$ (Deinococcus maricopensis) to $86.7 \%$ (Deinococcus hopiensis). A phylogenetic tree reconstructed using the maximum-likelihood algorithm and including all the type species of the genera Deinococcus and Truepera demonstrated that strain $\mathrm{K} 4.1^{\mathrm{T}}$ forms a distinct line of descent branching at the base of the genus Deinococcus (Supplementary Fig. S4). A separate phylogenetic position of strain $\mathrm{K} 4.1^{\mathrm{T}}$ was also obtained using neighbour-joining and maximum-parsimony algorithms (Supplementary Fig. S4). Neighbour-joining and maximum-parsimony bootstrap analysis yielded high support for a phylogenetic position separate from both the genera Deinococcus and Truepera (Supplementary Fig. S4).

Polar lipids were extracted and analysed by two-dimensional thin layer chromatography as described previously (Altenburger et al., 1996; Tindall, 1990a, b). Strain K4.1 ${ }^{\mathrm{T}}$ was grown for 2 days at $45{ }^{\circ} \mathrm{C}$ on $3.3 \times$ PYE agar. Truepera 
radiovictrix DSM $17093^{\mathrm{T}}$ was grown on thermus agar, which is essentially $0.33 \times \mathrm{PYE}$ agar supplemented with $\mathrm{FeCl}_{3}$ and trace elements, for 3 days at $45{ }^{\circ} \mathrm{C}$. The predominant lipid of strain $\mathrm{K} 4.1^{\mathrm{T}}$ was an unknown aminophospholipid (APL1). In addition, the lipid profile consisted of two other aminophospholipids, one unknown phospholipid, four unknown glycolipids, two unknown aminolipids and one unknown polar lipid. This lipid profile is quite unusual compared to species of the genus Deinococcus, which have been reported to contain an unknown phosphoglycolipid as the predominant lipid (with the exception of Deinococcus yavapaiensis; Rainey et al., 2005) and other phosphoglycolipids as well (Callegan et al., 2008; Kämpfer et al., 2008; Ferreira et al., 1997; Embley et al., 1987; Weon et al., 2007; Zhang et al., 2007). No phosphoglycolipids were detected in strain K4.1 ${ }^{\mathrm{T}}$ (Fig. 2a). Chromatographic analysis of a mixture of lipid extracts of strain $\mathrm{K} 4.1^{\mathrm{T}}$ and Deinococcus grandis on the same thin layer plate demonstrated that APL1 and the predominant phosphoglycolipid specific for deinococci exhibited almost identical chromatographic behaviour (results not shown) and thus the two lipids can only be distinguished by their different staining behaviour. However, to the best of our knowledge, the presence of the major lipid APL1 together with the absence of phosphoglycolipids distinguish strain $\mathrm{K} 4.1^{\mathrm{T}}$ from all species of the genus Deinococcus examined for polar lipids, including the type species of the genus, Deinococcus radiodurans (Embley et al., 1987), and its close phylogenetic relatives that might form the core of a redefined genus Deinococcus such as Deinococcus radiopugnans, Deinococcus ficus, Deinococcus deserti, Deinococcus frigens, Deinococcus saxicola and Deinococcus marmoris (Hirsch et al., 2004; de Groot et al., 2005; Embley et al., 1987; Lai et al., 2006). Reanalysis of the polar lipids of Truepera radiovictrix confirmed the observation that it contains a complex mixture of glycolipids and phospholipids (Albuquerque et al., 2005). The polar lipid profile of Truepera radiovictrix was composed of eleven glycolipids, two phospholipids, one aminolipid and two lipids not staining with specific spray reagents such as ninhydrin, molybdenum blue or $\alpha$-naphthol (Fig. 2b). This lipid profile was substantially different from that of strain K4.1 $1^{\mathrm{T}}$. The major aminolipid of strain $\mathrm{K} 4.1^{\mathrm{T}}$ (APL1) was not detectable in Truepera radiovictrix and conversely, the major compound, phospholipid PL1, and several glycolipids were not found in strain $\mathrm{K} 4.1^{\mathrm{T}}$. These data demonstrate that strain $\mathrm{K} 4.1^{\mathrm{T}}$ can unambiguously be distinguished from Truepera radiovictrix based on the polar lipid profile.

The peptidoglycan structure of strain $\mathrm{K} 4.1^{\mathrm{T}}$ was analysed according to Schleifer (1985). The analysis revealed the peptidoglycan type as A3 $\beta$ with L-Orn-Gly-Gly, also found in representatives of the genera Deinococcus (Hirsch et al., 2004; Embley et al., 1987; Rainey et al., 1997), Thermus and Meiothermus (da Costa et al., 2001). DNA G +C content was determined with HPLC as $66.8 \mathrm{~mol} \%$. The peptidoglycan and DNA base composition were analysed at DSMZ (German Collection of Microorganisms and Cell Cultures, Germany).

Whole-cell fatty acids of strain $\mathrm{K} 4.1^{\mathrm{T}}$ were analysed from biomass grown at $28{ }^{\circ} \mathrm{C}$ [TSBA (TSB with $15 \mathrm{~g} \mathrm{l}^{-1}$ agar), 1 day] and at $45{ }^{\circ} \mathrm{C}$ [TSBA, 1 day; R2A, 2 days; thermus agar (DSMZ medium 1033), 2 days] as methyl esters

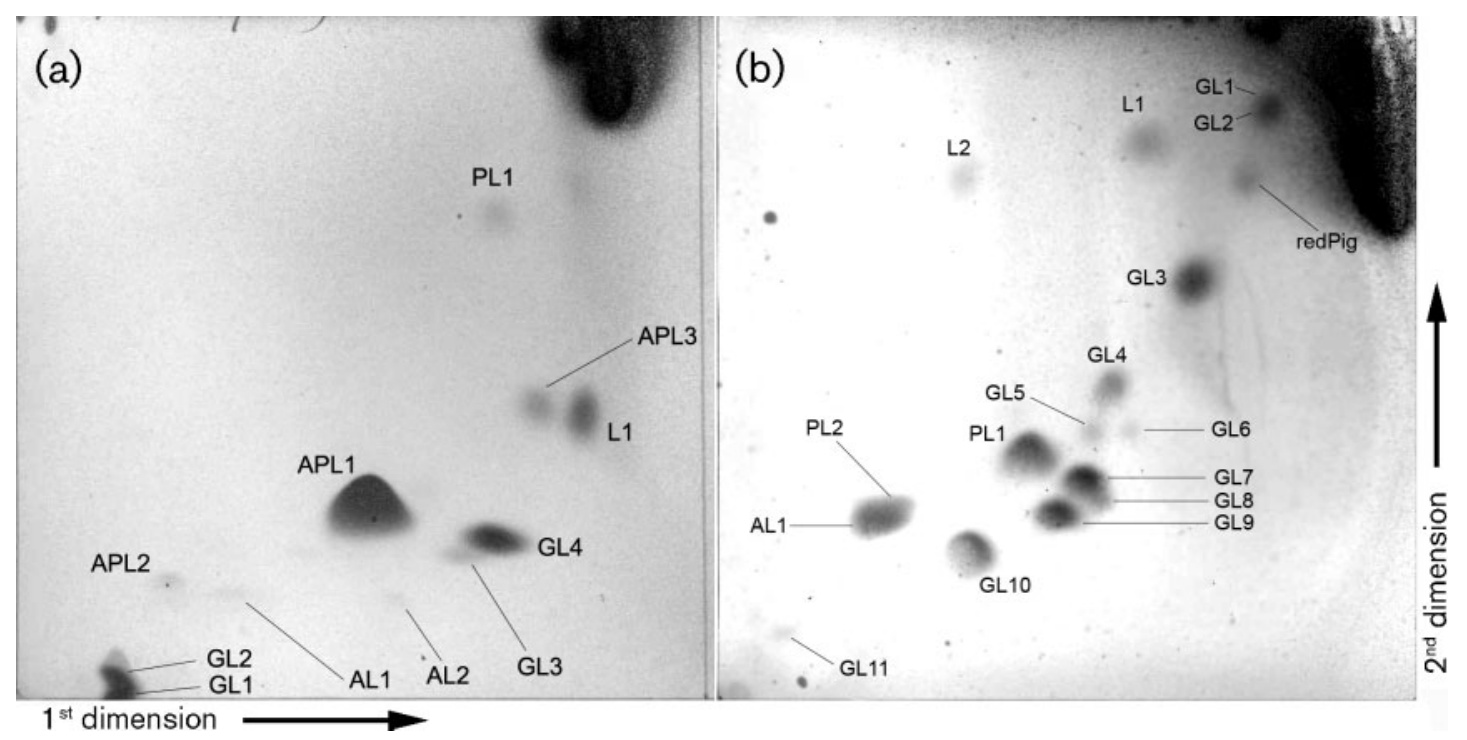

Fig. 2. Polar lipid profile of strain $\mathrm{K} 4.1^{\top}$ (a) and Truepera radiovictrix (b) after detection with molybdate phosphoric acid. APL13, unknown aminophospholipids; AL1,2, unidentified aminolipids; GL1-11, unidentified glycolipids; L1,2, unidentified polar lipids not detectable with any of the specific spray reagents; PL1,2, unidentified phospholipids; redPig, red pigment. Same labels in the two images do not indicate that the corresponding spots represent the same lipid. 
derivatized according to the protocol of MIDI (MIDI, 2001). The main fatty acids of strain $\mathrm{K} 4.1^{\mathrm{T}}$ were $15: 0$ iso, $15: 0$ anteiso, $17: 0$ iso and 17:0 anteiso (Table 1). Strain $\mathrm{K} 4.1^{\mathrm{T}}$ adapted to growth at temperatures below the optimum by synthesizing unsaturated $15: 1$ anteiso acid. It differed from species of the genus Deinococcus (Tables 1, 2 and Supplementary Table S1) by the absence of straight chain unsaturated fatty acids, which are the major components in most deinococci. Unbranched fatty acids were found only in minute amounts in strain $\mathrm{K} 4.1^{\mathrm{T}}$ in contrast to the deinococci. Instead, branched fatty acids constituted over $90 \%$ of the fatty acids at both 45 and $28{ }^{\circ} \mathrm{C}$ and in peptone rich (TSBA) and low peptone medium (R2A). Hydroxy fatty acids (17:0 iso $3-\mathrm{OH}$ and $17: 02-\mathrm{OH})$ were also found in strain $\mathrm{K} 4.1^{\mathrm{T}}$. Those were absent or scarce in deinococci.

Respiratory quinones were extracted and analysed as described by Tindall $(1990 \mathrm{a}, \mathrm{b})$. Strain K4.1 ${ }^{\mathrm{T}}$ contained menaquinone MK-8, which is the major quinone of all genera in the phylum Deinococcus-Thermus (Albuquerque et al., 2005; Rainey et al., 2007; Miroshnichenko et al., 2003).

The phylogenetic distance of strain $\mathrm{K} 4.1^{\mathrm{T}}$ to the genus Deinococcus is large (16S rRNA similarity 90-86.7\%) but smaller than that to the genus Truepera (similarity $85.3 \%$ ).

Table 1. Whole-cell fatty acids (\% of total) of strain $\mathrm{K} 4.1^{\top}$, Truepera radiovictrix DSM $17093^{\top}$ and deinococci (D. radiodurans $\mathrm{DSM}$ $20539^{\top}$, D. radiopugnans ATCC $19172^{\top}$, D. grandis DSM $3963^{\top}$ )

The major fatty acids $(>5 \%)$ are highlighted by means of bold type. Fatty acids that represent less than $1 \%$ in all species are not shown.,$-<0.1 \%$.

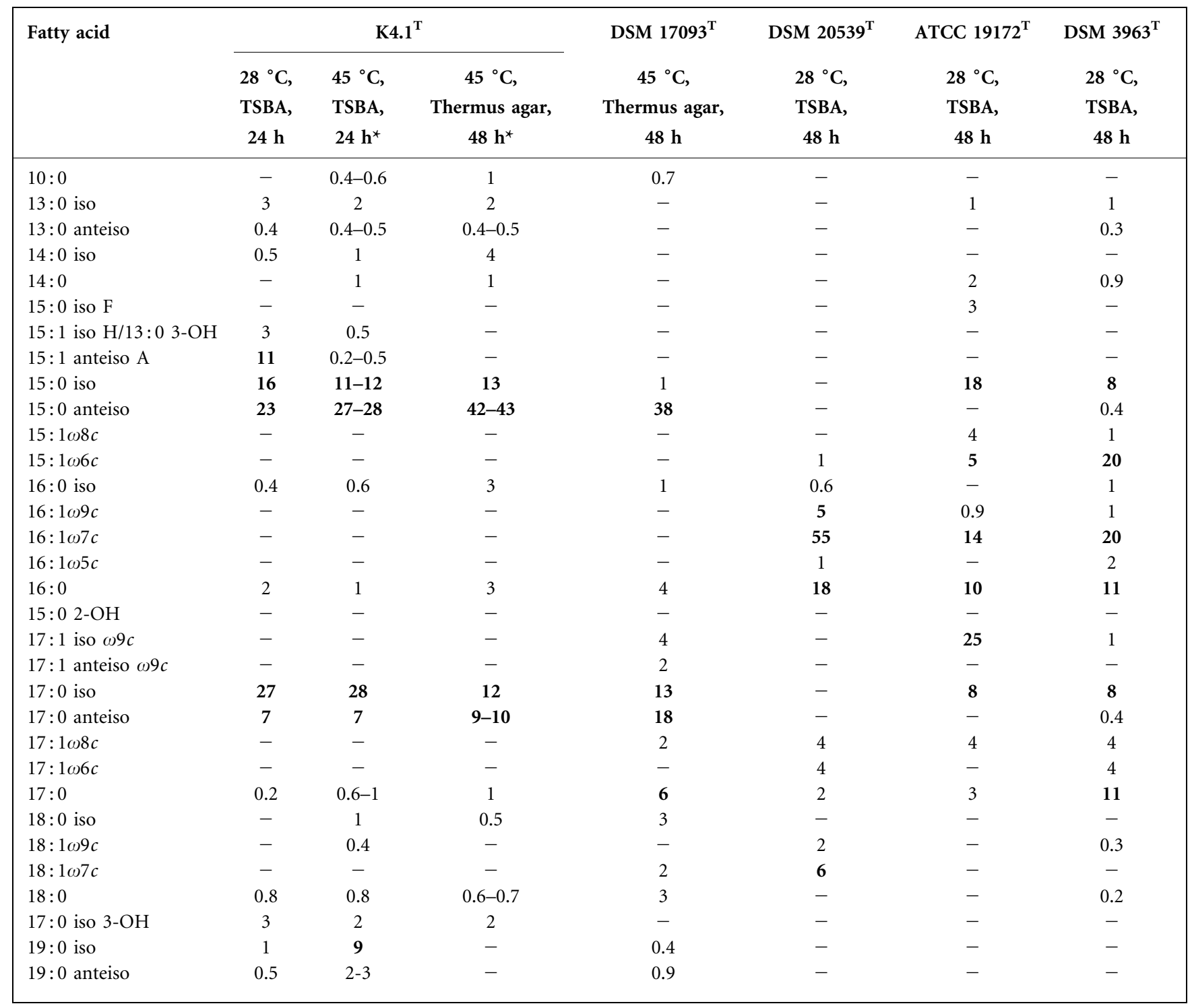

${ }^{\star}$ Fatty acids were extracted and analysed twice. 
Table 2. The major discriminative properties between the genera Deinobacterium gen. nov., Deinococcus and Truepera

$16 \mathrm{~S}$ rRNA gene similarities are based on similarity table analysis (Chun et al., 2007). Data for strain K4.1 ${ }^{\mathrm{T}}$ is from this study. Since the genus Deinococcus is heterogeneous, it was divided into 8 clades based on their fatty acid compositions. Full fatty acid compositions and growth conditions are presented in Supplementary Table S1. APL, Unknown aminophospholipid; PGL, unknown phosphoglycolipid; GL, unknown glycolipids; Dalt, D. altitudinis; Dapa, D. apachensis; Daqc, D. aquaticus; Dcae, D. caeni; Dcel, D. cellulosilyticus; Dcla, D. claudionis; Ddes, D. deserti; Dfic, D. ficus; Dfri, D. frigens; Dgob, D. gobiensis; Dgra, D. grandis; Dhoh, D. hohokamensis; Dhop, D. hopiensis; Dind, D. indicus; Dmis, D. misasensis; Dmrm, D. marmoris; Dmur, D. murrayi; Dnav, D. navajoensis; Dpim, D. pimensis; Drdr, D. radiodurans; Drml, D. radiomollis; Dros, D. roseus; Dsax, D. saxicola; Dyav, D. yavapaiensis. The following species represented solitary patterns of whole-cell fatty acids: D. aquatilis, D. geothermalis, D. radiopugnans, D. papagonensis, D. sonorensis, D. alpitundrae, D. aquiradiocola, D. aerius, D. peraridilitoris, D. yunweiensis, D. xingjiangensis, D. proteolyticus and D. radiophilus. Polar lipid and fatty acid data of the genera Deinococcus and Truepera were collected from the species description articles (Albuquerque et al., 2005; Asker et al., 2008, 2009; Callegan et al., 2008; de Groot et al., 2005; Ferreira et al., 1997; Hirsch et al., 2004; Im et al., 2008; Kämpfer et al., 2008; Lai et al., 2006; Peng et al., 2009; Rainey et al., 2005, 2007; Weon et al., 2007; Yang et al., 2009; Yuan et al., 2009; Zhang et al., 2007).

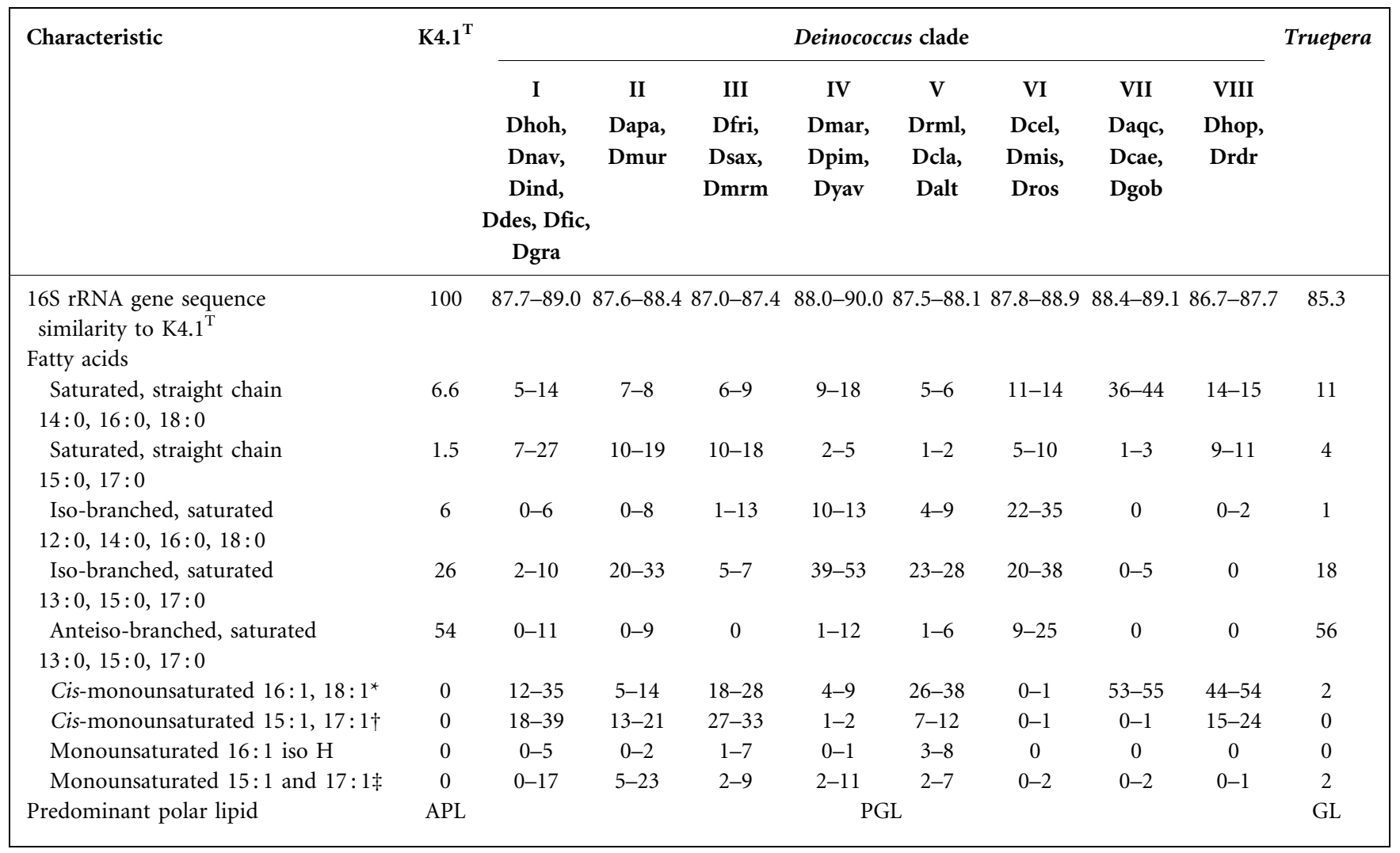

${ }^{\star} 16: 1 \omega 9 c, 16: 1 \omega 7 c, 16: 1 \omega 5 c, 18: 1 \omega 9 c, 18: 1 \omega 7 c$.

$\dagger 15: 1 \omega 8 c, 15: 1 \omega 6 c, 17: 1 \omega 8 c, 17: 1 \omega 6 c, 17: 1 \omega 5 c$.

$\$ 15: 1$ iso I, $15: 1$ iso F, $15: 1$ anteiso A, $17: 1$ iso $\omega 9$ c.

The polar lipid profile (aminophospholipid as the predominant compound and no phosphoglycolipids) and fatty acid profile (dominated by branched-chain fatty acids and lacking unsaturated fatty acids) distinguish strain K4. $1^{\mathrm{T}}$ from the different Deinococcus clades (Table 2). A significantly different polar lipid profile and peptidoglycan type $\mathrm{A} 3 \beta$ distinguish strain $\mathrm{K} 4.1^{\mathrm{T}}$ from the genus Truepera. Further phenotypic traits distinguishing strain $\mathrm{K} 4.1^{\mathrm{T}}$ from the genus Truepera are lower tolerance to alkali $(\mathrm{pH} \leqslant 10.3$, Truepera $\mathrm{pH} \leqslant 11.2$ ) and salt (no growth in $5 \%$, Truepera grows in $6 \% \mathrm{NaCl}$ ) and lower growth temperature range (optimum around $40{ }^{\circ} \mathrm{C}$, no growth at $55^{\circ} \mathrm{C}$ ) than members of the genus Truepera (optimum $\left.50{ }^{\circ} \mathrm{C}\right)$. We conclude that these observations justify the proposal of a novel genus for strain $\mathrm{K} 4.1^{\mathrm{T}}$ in the family Deinococcaceae.

\section{Description of Deinobacterium gen. nov.}

Deinobacterium (Dei.no.bac.te'ri.um. Gr. adj. deinos gigantic, unusual; L. neut. n. bacterium rod, N.L. neut. n. Deinobacterium an unusual bacterium).

Aerobic and chemo-organotrophic. Non-motile and endospores are not formed. Catalase-positive. The major cellular 
fatty acids are branched 15:0 and 17:0 acids and the major polar lipid is an unknown aminophospholipid. MK-8 is the major respiratory quinone and the peptidoglycan structure is A3 $\beta \mathrm{L}-\mathrm{Orn}-\mathrm{Gly}-\mathrm{Gly}$. DNA G $+\mathrm{C}$ content is $67 \mathrm{~mol} \%$. The type species is Deinobacterium chartae.

\section{Description of Deinobacterium chartae sp. nov.}

Deinobacterium chartae (char'tae. L. gen. fem. n. chartae of/ from paper).

Exhibits the following properties in addition to those given in the genus description. Plate-grown cells are $0.8-1.3 \mu \mathrm{m}$ in width and $1.4-2.5 \mu \mathrm{m}$ in length, may grow to filaments up to $40 \mu \mathrm{m}$ in rich liquid medium. Stains Gram-negatively, but has features of Gram-positive cells. Catalase and oxidase-positive, urease-negative. Forms colonies with pale pink pigment on R2A agar. Growth occurs at 12 to $50{ }^{\circ} \mathrm{C}$ (optimum 37 to $45^{\circ} \mathrm{C}$ ) and between $\mathrm{pH} 6$ and 10.3. Growth is inhibited in the presence of $>3 \%(\mathrm{w} / \mathrm{v}) \mathrm{NaCl}$. Anaerobic growth does not occur on TSA. Produces acid from glucose, fructose and maltose. Utilizes as a carbon source: succinic acid, L-aspartic acid, glycerol, L-fucose, D-gluconic acid, Dxylose, D-glucose 6-phosphate, D-galactonic acid $\gamma$-lactone, L-asparagine, D-aspartic acid, D-glucosaminic acid, L-glutamine, $m$-tartaric acid, D-glucose 1-phosphate, glycyl Laspartic acid, citric acid, myo-inositol, D-threonine, fumaric acid, bromosuccinic acid, propionic acid, glycolic acid, Lalanine, acetoacetic acid, methyl pyruvate, $p$-hydroxyphenylacetic acid, $m$-hydroxyphenylacetic acid, glucuronamide, D-galacturonic acid, phenylethylamine, chondroitin sulfate C, $\gamma$-cyclodextrin, dextrin, gelatin, glycogen, D-arabinose, arbutin, 3-O- $\beta$-D-galactopyranosyl-D-arabinose, gentiobiose, lactitol, $\beta$-methyl D-galactoside, palatinose, raffinose, salicin, D-tagatose, turanose, butyric acid, caproic acid, D-glucosamine, $\alpha$-ketovaleric acid, 5-keto-D-gluconic acid, malonic acid, oxalomalic acid, L-histidine, dihydroxyacetone, melibionic acid, $\mathrm{N}$-acetyl-D-glucosaminitol, L-lysine and 3-hydroxy-2-butanone but not malate, cellobiose, D-galactose, L-arabinose, $N$-acetyl-D-glucosamine, D-saccharic acid, trehalose, D-mannose, dulcitol, D-serine, D-sorbitol, DL- $\alpha$-glycerol phosphate, L-glutamic acid, Tween 20, $\mathrm{D}$-fructose, acetic acid, $\alpha$-D-glucose, maltose, 1,2-propanediol, $\alpha$-ketoglutaric acid, sucrose, uridine, adonitol, mucic acid, tricarballylic acid, L-threonine, L-malic acid, pyruvic acid, L-galactonic acid $\gamma$-lactone, capric acid, D-lactic acid methyl ester, L-ornithine, $\mathrm{N}$-acetylneuraminic acid, L-phenylalanine, $\beta$-D-allose, sedoheptulosan, citraconic acid, amygdalin, citramalic acid, L-valine, glycine, DL-carnitine, D-arabitol, methyl $\alpha$-D-glucoside, 2-hydroxybenzoic acid, quinic acid, sec-butylamine, L-arabitol, 4-hydroxybenzoic acid, D-ribono-1,4-lactone, L-homoserine, DL-octopamine, xylitol, sebacic acid, L-hydroxyproline, putrescine, inulin, 2deoxy-D-ribose, methyl $\beta$-D-glucuronic acid, sorbic acid, ierythritol, methyl $\alpha$-D-mannoside, $\gamma$-aminobutyric acid, succinamic acid, methyl $\beta$-D-xyloside, $\delta$-aminovaleric acid, D-tartaric acid, L-tartaric acid or 2,3-butanone. Utilizes as a nitrogen source: L-alanine, L-glutamine, L-histidine, L-proline, D-glucosamine, D-galactosamine, D-mannosamine, adenosine, cytidine, guanine, guanosine, thymidine, uridine, inosine, uric acid, alloxan, Ala-Asp, Ala-Gln, Ala-Glu, AlaHis, Ala-Leu, Ala-Thr and Gly-Gln. Does not utilize as a nitrogen source: ammonia, nitrite, nitrate, urea, biuret, L-arginine, L-aspartic acid, glycine, L-methionine, L-valine, D-valine, L-citrulline, L-homoserine, L-ornithine, $\mathrm{N}$-acetyl DL-glutamic acid, $\mathrm{N}$-phthaloyl L-glutamic acid, L-pyroglutamic acid, hydroxylamine, methylamine, $\mathrm{N}$-butylamine, ethylamine, ethanolamine, ethylenediamine, putrescine, agmatine, $\beta$-phenylethylamine, tyramine, formamide, DL-lactamide, $N$-acetyl-D-galactosamine, adenine, cytosine, uracil, parabanic acid, $\gamma$-amino- $N$-butyric acid, $\varepsilon$-amino- $N$ caproic acid or $\delta$-amino- $N$-valeric acid. Utilizes as a phosphorus source: adenosine $5^{\prime}$-monophosphate, guanosine $5^{\prime}$-monophosphate, uridine $5^{\prime}$-monophosphate and thymidine $5^{\prime}$-monophosphate. Does not utilize as a phosphorus source: phosphate, trimetaphosphate, tripolyphosphate, triethyl phosphate, hypophosphite, adenosine $2^{\prime}$-monophosphate, adenosine $3^{\prime}$-monophosphate, adenosine $2^{\prime}, 3^{\prime}$-cyclic monophosphate, adenosine $3^{\prime}, 5^{\prime}$ cyclic monophosphate, guanosine $3^{\prime}$-monophosphate, guanosine $2^{\prime}, 3^{\prime}$-cyclic monophosphate, guanosine $3^{\prime}, 5^{\prime}$ cyclic monophosphate, cytidine $3^{\prime}$-monophosphate, cytidine $2^{\prime}, 3^{\prime}$-cyclic monophosphate, cytidine $3^{\prime}, 5^{\prime}$-cyclic monophosphate, uridine $2^{\prime}$-monophosphate, uridine $3^{\prime}$ monophosphate, uridine $2^{\prime}, 3^{\prime}$-cyclic monophosphate, uridine $3^{\prime}, 5^{\prime}$-cyclic monophosphate, guanosine $2^{\prime}$-monophosphate, DL- $\alpha$-glycerol phosphate, $\beta$-glycerol phosphate, carbamyl phosphate, D-2-phosphoglyceric acid, phosphoglycolic acid, 2-deoxy-D-glucose 6-phosphate, 6-phosphogluconic acid, D-mannose 1-phosphate, D-mannose 6phosphate, cysteamine-S-phosphate, phospho-L-arginine, $O$-phospho-D-serine, O-phospho-L-threonine, phosphocreatine, phosphorylcholine, $O$-phosphorylethanolamine, phosphonoacetic acid, 2-aminoethylphosphonic acid, thymidine $3^{\prime}$-monophosphate, inositol hexaphosphate or thymidine $3^{\prime}, 5^{\prime}$-cyclic monophosphate. The fatty acid composition is listed in Table 1 . MK- 8 is the only respiratory quinone. The lipid profile consists of three unknown aminophospholipids, of which one is the predominant lipid, one unknown phospholipid, four unknown glycolipids, two unknown aminolipids and one unknown polar lipid. Peptidoglycan structure is $A 3 \beta$ L-Orn-Gly-Gly and the DNA G + C content of the type strain is $66.8 \mathrm{~mol} \%$. May be grown on R2A or TSA at $45{ }^{\circ} \mathrm{C}$ in ambient air.

The type strain, K4.1 ${ }^{\mathrm{T}}\left(=\right.$ DSM $21458^{\mathrm{T}}=$ HAMBI $\left.2721^{\mathrm{T}}\right)$, was isolated from a biofilm collected from a Finnish paper mill.

\section{Acknowledgements}

We thank Hans G. Trüper for creatively suggesting a name for this new species, Mirva Kosonen for the 16S rRNA gene sequencing, Anna 
Peltola for laboratory assistance, Anna Pal for the lipid work and Martti Hakanen for helping in the irradiation experiment. We thank the Finnish graduate school EnSTe (JE) and Academy of Finland for the Centre of Excellence grant (Photobiomics, grant no. 118637). We also thank Helsinki University Viikki Science Library for excellent information service, the Faculty of Agriculture and Forestry Instrument Centre for technical support and Leena Steininger, Hannele Tukiainen and Tuula Suortti for many kinds of help.

\section{References}

Albuquerque, L., Simões, C., Nobre, M. F., Pino, N. M., Battista, J. R., Silva, M. T., Rainey, F. A. \& da Costa, M. S. (2005). Truepera radiovictrix gen. nov., sp. nov., a new radiation resistant species and the proposal of Trueperaceae fam. nov. FEMS Microbiol Lett 247, 161169.

Altenburger, P., Kämpfer, P., Makristathis, A., Lubitz, W. \& Busse, H.-J. (1996). Classification of bacteria isolated from a medieval wall painting. J Biotechnol 47, 39-52.

Asker, D., Awad, T. S., Beppu, T. \& Ueda, K. (2008). Deinococcus misasensis and Deinococcus roseus, novel members of the genus Deinococcus, isolated from a radioactive site in Japan. Syst Appl Microbiol 31, 43-49.

Asker, D., Awad, T. S., Beppu, T. \& Ueda, K. (2009). Deinococcus aquiradiocola sp. nov., isolated from a radioactive site in Japan. Int $J$ Syst Evol Microbiol 59, 144-149.

Battista, J. R. \& Rainey, F. A. (2001). Genus I. Deinococcus Brooks and Murray 1981. In Bergey's Manual of Systematic Bacteriology 2nd edn, vol. 1, pp. 396-403. Edited by D. R. Boone, R. W. Castenholz \& G. M. Garrity. New York: Springer.

Bruno, W. J., Socci, N. D. \& Halpern, A. L. (2000). Weighted neighbor joining: a likelihood-based approach to distance-based phylogeny reconstruction. Mol Biol Evol 17, 189-197.

Callegan, R. P., Nobre, M. F., McTernan, P. M., Battista, J. R., NavarroGonzález, R., McKay, C. P., da Costa, M. S. \& Rainey, F. A. (2008). Description of four novel psychrophilic, ionizing radiation-sensitive Deinococcus species from alpine environments. Int J Syst Evol Microbiol 58, 1252-1258.

Chun, J., Lee, J.-H., Jung, Y., Kim, M., Kim, S., Kim, B. K. \& Lim, Y. W. (2007). EzTaxon: a web-based tool for the identification of prokaryotes based on $16 \mathrm{~S}$ ribosomal RNA gene sequences. Int J Syst Evol Microbiol 57, 2259-2261.

da Costa, M. S., Nobre, M. F. \& Rainey, F. A. (2001). Genus I. Thermus Brock and Freeze 1969. In Bergey's Manual of Systematic Bacteriology, 2nd edn, vol. 1, pp. 404-414. Edited by D. R. Boone, R. W. Castenholz \& G. M. Garrity. New York: Springer.

de Groot, A., Chapon, V., Servant, P., Christen, R., Fischer-Le Saux, M., Sommer, S. \& Heulin, T. (2005). Deinococcus deserti sp. nov., a gammaradiation-tolerant bacterium isolated from the Sahara Desert. Int J Syst Evol Microbiol 55, 2441-2446.

Embley, T. M., O’Donnell, A. G., Wait, R. \& Rostron, J. (1987). Lipid and cell wall amino acid composition in the classification of members of the genus Deinococcus. Syst Appl Microbiol 10, 20-27.

Ferreira, A. C., Nobre, M. F., Rainey, F. A., Silva, M. T., Wait, R., Burghardt, J., Chung, A. P. \& da Costa, M. S. (1997). Deinococcus geothermalis sp. nov. and Deinococcus murrayi sp. nov., two extremely radiation-resistant and slightly thermophilic species from hot springs. Int J Syst Bacteriol 47, 939-947.

Halinen, K., Fewer, D. P., Sihvonen, L. M., Lyra, C., Eronen, E. \& Sivonen, K. (2008). Genetic diversity in strains of the genus Anabaena isolated from planktonic and benthic habitats of the Gulf of Finland (Baltic Sea). FEMS Microbiol Ecol 64, 199-208.
Hirsch, P., Gallikowski, C. A., Siebert, J., Peissl, K., Kroppenstedt, R., Schumann, P., Stackebrandt, E. \& Anderson, R. (2004). Deinococcus frigens sp. nov., Deinococcus saxicola sp. nov., and Deinococcus marmoris sp. nov., low temperature and draught-tolerating, UV-resistant bacteria from continental Antarctica. Syst Appl Microbiol 27, 636-645.

Im, W.-T., Jung, H.-M., Ten, L. N., Kim, M. K., Bora, N., Goodfellow, M., Lim, S., Jung, J. \& Lee, S.-T. (2008). Deinococcus aquaticus sp. nov., isolated from fresh water, and Deinococcus caeni sp. nov., isolated from activated sludge. Int J Syst Evol Microbiol 58, 2348-2353.

Kämpfer, P., Lodders, N., Huber, B., Falsen, E. \& Busse, H. J. (2008). Deinococcus aquatilis sp. nov., isolated from water. Int J Syst Evol Microbiol 58, 2803-2806.

Kolari, M., Nuutinen, J., Rainey, F. A. \& Salkinoja-Salonen, M. S. (2003). Colored moderately thermophilic bacteria in paper-machine biofilms. J Ind Microbiol Biotechnol 30, 225-238.

Lai, W.-A., Kämpfer, P., Arun, A. B., Shen, F.-T., Huber, B., Rekha, P. D. \& Young, C.-C. (2006). Deinococcus ficus sp. nov., isolated from the rhizosphere of Ficus religiosa L. Int J Syst Evol Microbiol 56, 787-791.

MacFaddin, J. F. (2000). Biochemical Tests for Identification of Medical Bacteria, 3rd edn. Philadelphia, PA: Lippincott Williams \& Wilkins.

MIDI (2001). Sherlock Microbial Identification System Operating Manual, version 4.0. Newark, DE: MIDI, Inc.

Miroshnichenko, M. L., L'Haridon, S., Nercessian, O., Antipov, A. N., Kostrikina, N. A., Tindall, B. J., Schumann, P., Spring, S., Stackebrandt, E. \& other authors (2003). Vulcanithermus mediatlanticus gen. nov., sp. nov., a novel member of the family Thermaceae from a deep-sea hot vent. Int J Syst Evol Microbiol 53, 1143-1148.

Omelchenko, M. V., Wolf, Y. I., Gaidamakova, E. K., Matrosova, V. Y., Vasilenko, A., Zhai, M., Daly, M. J., Koonin, E. V. \& Makarova, K. S. (2005). Comparative genomics of Thermus thermophilus and Deinococcus radiodurans: divergent routes of adaptation to thermophily and radiation resistance. BMC Evol Biol 5, 57.

Peltola, M., Kanto Öqvist, C., Ekman, J., Kosonen, M., Jokela, S., Kolari, M., Korhonen, P. \& Salkinoja-Salonen, M. (2008). Quantitative contributions of bacteria and of Deinococcus geothermalis to deposits and slimes in paper industry. J Ind Microbiol Biotechnol 35, 1651-1657.

Peng, F., Zhang, L., Luo, X., Dai, J., An, H., Tang, Y. \& Fang, C. (2009). Deinococcus xinjiangensis sp. nov., isolated from desert soil. Int J Syst Evol Microbiol 59, 709-713.

Rainey, F. A., Nobre, M. F., Schumann, P., Stackebrandt, E. \& da Costa, M. S. (1997). Phylogenetic diversity of the deinococci as determined by $16 \mathrm{~S}$ ribosomal DNA sequence comparison. Int J Syst Bacteriol 47, 510-514.

Rainey, F. A., Ray, K., Ferreira, M., Gatz, B. Z., Nobre, M. F., Bagaley, D., Rash, B. A., Park, M.-J., Earl, A. M. \& other authors (2005). Extensive diversity of ionizing-radiation-resistant bacteria recovered from Sonoran Desert soil and description of nine new species of the genus Deinococcus obtained from a single soil sample. Appl Environ Microbiol 71, 5225-5235.

Rainey, F. A., Ferreira, M., Nobre, M. F., Ray, K., Bagaley, D., Earl, A. M., Battista, J. R., Gómez-Silva, B., McKay, C. P. \& da Costa, M. S. (2007). Deinococcus peraridilitoris sp. nov., isolated from a coastal desert. Int J Syst Evol Microbiol 57, 1408-1412.

Raulio, M., Järn, M., Ahola, J., Peltonen, J., Rosenholm, J. B., Tervakangas, S., Kolehmainen, J., Ruokolainen, T., Narko, P. \& Salkinoja-Salonen, M. (2008). Microbe repelling coated stainless steel analysed by field emission scanning electron microscopy and physicochemical methods. J Ind Microbiol Biotechnol 35, 751-760.

Schleifer, K. H. (1985). Analysis of the chemical composition and primary structure of murein. Methods Microbiol 18, 123-156. 
Tijssen, J. P. F., Beekes, H. W. \& Van Steveninck, J. (1982). Localization of polyphosphates in Saccharomyces fragilis, as revealed by 4',6-diamidino-2-phenylindole fluorescence. Biochim Biophys Acta 721, 394-398.

Tindall, B. J. (1990a). A comparative study of the lipid composition of Halobacterium saccharovorum from various sources. Syst Appl Microbiol 13, 128-130.

Tindall, B. J. (1990b). Lipid composition of Halobacterium lacusprofundi. FEMS Microbiol Lett 66, 199-202.

Weon, H.-Y., Kim, B.-Y., Schumann, P., Son, J.-A., Jang, J., Go, S.-J. \& Kwon, S.-W. (2007). Deinococcus cellulosilyticus sp. nov., isolated from air. Int J Syst Evol Microbiol 57, 1685-1688.

Yang, Y., Itoh, T., Yokobori, S., Itahashi, S., Shimada, H., Satoh, K., Ohba, H., Narumi, I. \& Yamagishi, A. (2009). Deinococcus aerius sp. nov., isolated from the high atmosphere. Int J Syst Evol Microbiol 59, 1862-1866.

Yuan, M., Zhang, W., Dai, S., Wu, J., Wang, Y., Tao, T., Chen, M. \& Lin, M. (2009). Deinococcus gobiensis sp. nov., an extremely radiation-resistant bacterium. Int J Syst Evol Microbiol 59, 1513-1517.

Zhang, Y. Q., Sun, C. H., Li, W. J., Yu, L. Y., Zhou, J. Q., Zhang, Y. Q., Xu, L. H. \& Jiang, C. L. (2007). Deinococcus yunweiensis sp. nov., a gamma- and UV-radiation-resistant bacterium from China. Int J Syst Evol Microbiol 57, 370-375.

Zimmerman, J. M. \& Battista, J. R. (2006). Measuring survival in microbial populations following exposure to ionizing radiation. In Extremophiles, Methods in Microbiology, vol. 35, pp. 745-754. Edited by F. A. Rainey \& A. Oren. London: Academic Press. 